\title{
The nonlinear analysis on cross-section short-limb shear wall
}

\author{
Zhang Qiang $^{1, a^{*}}$, Tao Cheng-cheng ${ }^{1, b}$ and Cao Wei-rong ${ }^{2, c}$ \\ ${ }^{1}$ Full address of first author, including country \\ ${ }^{1}$ College of Civil Engineering, Shanghai Normal University, Shanghai 201418, China \\ ${ }^{2}$ Tongzhou Construction General Contracting Group Co.,Ltd, Jiangsu 200433, China \\ azhq@shnu.edu.cn, b807298827@qq.com, 'btzjzcwr@163.com
}

Keywords: Cross-section short-limb shear wall, Axial compressive ratio, Nonlinear analysis, Load capacity Deformation capacity

Abstract: Nine cross-section reinforced-concrete short-limb shear wall specimens under monotonic load are analyzed by the nonlinear finite element analysis with the software ANSYS, which compares the change of load capacity, stiffness and ductility of the shear wall when axial compressive ratio changes. The results provides a significant basis for practical engineering section design.

\section{Introduction}

Short-limb shear wall structure system is flexibly arranged which is easy to satisfy various function of high-rise buildings and suffers little from seismic effect. And it has become a popular issue in academic field. Zhang Shou-jun ${ }^{[1-2]}$ and his fellows have analyzed the static elasto-plastic property of short-limb shear wall. Wang Jian-xiang ${ }^{[3]}$ and his fellows have undertaken the simulative test on L-shaped short-limb shear wall structure with ANSYS. Xiao Liang-li and his fellows ${ }^{[4-5]}$ have made use of the analysis of 3 T-shaped short-limbed wall specimens with flanges under horizontal cycling load by the nonlinear analysis. This article is based on the nonlinear analysis of reinforced-concrete cross-section short-limb shear wall structure and carries out the specimen program tests to draw the conclusion of the influence of the axial compressive ratio and some other factors on the failure pattern and failure load. At the same time, the ductility index of the structure is acquired and the real mechanical behavior of cross-section short-limb shear wall could be revealed.

\section{Model Design}

The separated model is used in this study. When setting the finite element model of cross- shaped short-limb shear wall, SOLID 65 unit is for concrete and Link8 is for steel. The ratio of specimens is 1:1. The thickness of the wall limb is $200 \mathrm{~mm}$, the width of long flange is $1160 \mathrm{~mm}$ and the width of short flange is $520 \mathrm{~mm}$. The total height of wall is $3.2 \mathrm{~m}$. The class levels of steel and bonding steel are $\Phi 10$ and $\Phi 6$.

In the test model, in order to avoid the crush breaking of concrete due to the stress centralization in the process of putting on load, the rigid beams which have the same sizes as the specimen sections are set over the specimens. The vertical and horizontal loads are both put on the rigid beams, which transform the forces to specimens. And the displacements of rigid beams and the specimen are considered as coordinated with each other in $\mathrm{x}, \mathrm{y}, \mathrm{z}$ directions without relative slides. As is shown in Fig. 1.
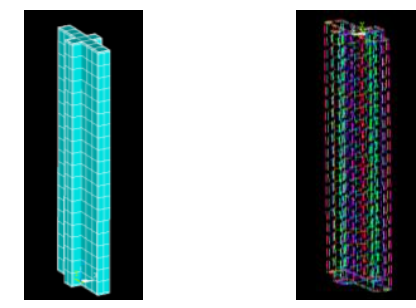

Fig. 1. The schematic diagram of calculation model 
In the test strength class of the steel is HPB235 (Q235), the strength design value is $210 \mathrm{~N} / \mathrm{mm} 2$ and the elastic modulus is $200 \mathrm{kN} / \mathrm{mm} 2$. Concrete C 30 is adopted in the test. The constitutive model is as follows:

A. The constitutive model of concrete

The adopted concrete constitutive model of skeleton curve is the model Kent ${ }^{[6]}$ and park introduced in 1973, which, afterwards was improved by Scott. The pattern respectively considered the mechanical characteristic of the restrained concrete and non-restrained one. The improved Berkeley model of the concrete unloading and reloading is adopted based on the Karson and Jirsa model. Its unloading and reloading are both expressed as linear pattern. The tension stress of concrete is neglected and considering the crack effect, shown in Fig.2.

B. The constitutive model of steel bar

The model is adopted shown in Fig.2. The steel bar skeleton curve under repetitive loading uses the 2 -linear model. The equivalent elastic modulus over the elastic limit is defined as $E^{\prime}=0.01 \mathrm{E}$. The closed parallelogram is combined by the skeleton curve, unloading curve and reloading curve, which showed that the elastic limit of the inverse loading decreased a little and the higher the stress is before unloading, the lower the elastic limit will be under the inverse loading. Therefore, this model partly considers the Bauschinger Effect, which is a simple and efficient steel bar constitutive model.

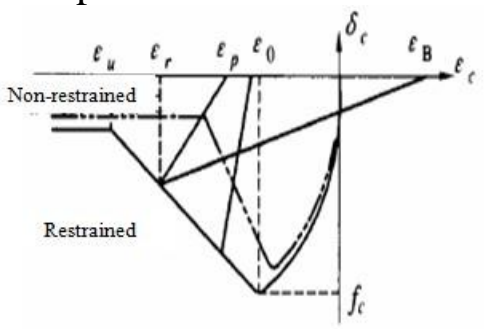

Fig. 2. Concrete constitution in the program

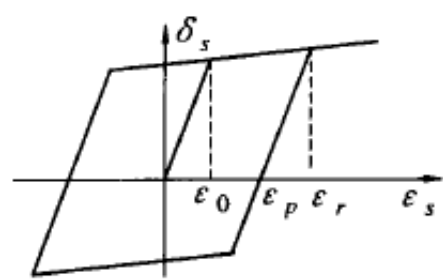

Fig. 3. Steel bar constitution in the program

When doing the simulating test, the bottom of the shear wall is totally restrained and the infinite stiffness of the floor slab is taken into consideration. As a result, the horizontal load is put on the top of the specimen with the method of concentrated force. When simulating the test, the axial load is put on the rigid beam at first, whose amount is determined by the designed axial compressive ratio of the test. In the whole process of the test, the magnitude of axial load keeps the same and then the horizontal load is gradually put on the specimen until the final failure.

\section{Analysis of Test Results}

A. Analysis of load capacity

When changes of axial compressive ratio are taken into consideration, the variety trends of cracking load, failure load and yield load are shown as Fig.4 and Fig. 5.

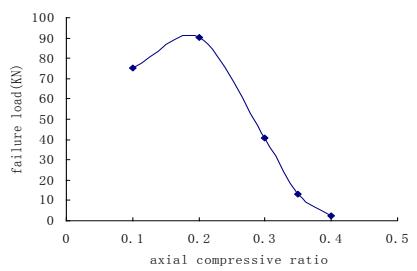

Fig. 4. The variety trend of cracking load with the change of axial compressive ratio

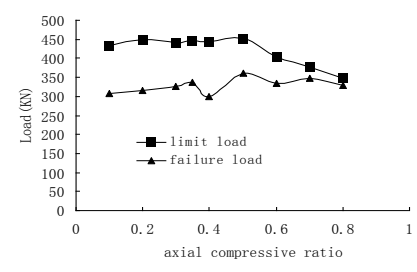

Fig. 5. The trends of the yield load and failure load with the change of the axial compressive

When limited into some range, the tensile stress of the section in tension could be counteracted because axial compressive load generate compressive stress on the section of short-limb shear wall system. In this way, the tensile stresses on concrete and steel bar decrease and the cracking load, failure load and yield load[2] of the specimen could increase. From Fig.5, the load capacity of cross-shape shear wall increases when axial compressive ratio is between 0.1 and 0.3 . When axial compressive ratio increases to more than 0.5 , load capacity will not increase obviously. At the same time, the yield strength increases with the increase of axial 
compressive ratio. Because of the effect of the axis load, the concrete at bottom would become cracking under compressive load if the axial compressive ratio is too high, which decrease the cracking load of the whole walling system. From the figure, it's most favorable when axial compressive ratio is about 0.3 .

B. Stiffness analysis

Because the hysteretic curve of the specimen almost keeps straight before the cracking point, it could be considered that the stiffness degradation starts from the cracking point. That is, assuming the stiffness keep almost the same before the cracking point, we could get the equivalent stiffness of the specimen through dividing the peak value by the relevant displacement. The ratio between equivalent stiffness and cracking stiffness is stiffness degradation coefficient. The variety trend of stiffness degradation coefficient with axial compressive ratio is shown in Fig, 6. Fig. 7 shows the curve diagram of displacements of specimens with different axial compressive ratios and equivalent stiffness degradation coefficient.

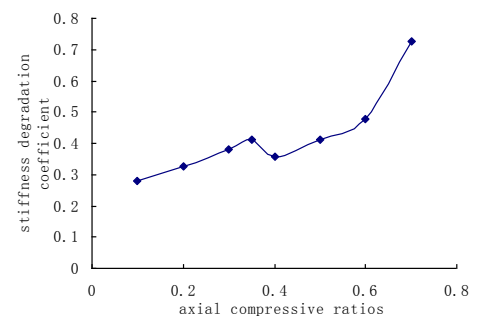

Fig. 6. The trend of stiffness degradation coefficient with the change of axial compressive ratios

From Fig. 6, stiffness degradation coefficient will increase with the increase of axial compressive ratio. C. Analysis of deformation capacity

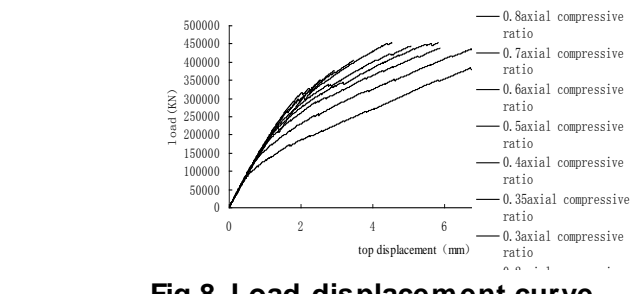

Fig.8. Load-displacement curve

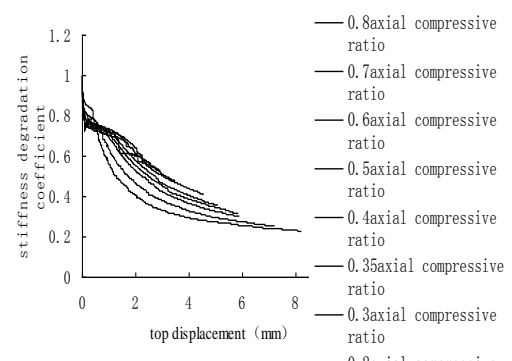

Fig.7 Stiffness degradation coefficient

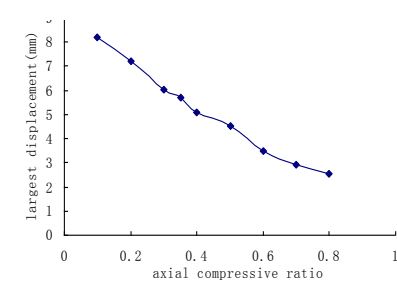

Fig. 9. The trend of largest displacement when axial compressive ratio changes

From Fig. 8, it could be concluded that the skeleton is almost straight at first because the specimens are in elastic phase, where the variety of initial stiffness and load capacity is not obvious. And than the curves gradually increase and the slopes become slow. The capacity load increase slowly in the positive direction but keep an increasing trend.

Among the structure earthquake-resistant properties, ductility is an important property, which is usually measured by ductility factor. From the elastic-plasticity response spectrum, the higher the ductility becomes, the lower of the earthquake load is.

In load-displacement skeleton curve, there is usually no obvious yield point, which is because of the nonlinear characteristic of the material and the different time when different steel part become yield. This article adopts the geometrograph to determine the yield displacement. Considering the change of axial compressive ratio, the trend of largest displacement and ductility factor is shown as Fig.9 and Fig.10.

When axial compressive ratio is very low, the ductility factor will increase with the increase of axial compressive ratio. But when axial compressive ratio continues to increase, the axial compressive load become larger and larger, and the ultimate displacement of the wall is less and less. That is, under the circumstance of the increasing compressive load, the ductility factor of wall decreases sharply, which means that the plastic property decreases obviously with the increase of axial compressive ratio. 


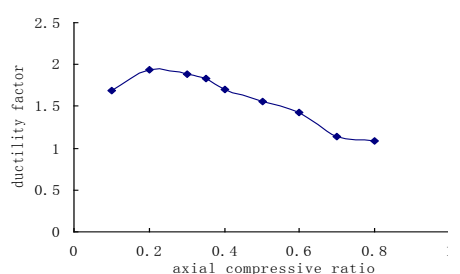

Fig. 10. The trend of ductility factor when axial compressive ratio changes

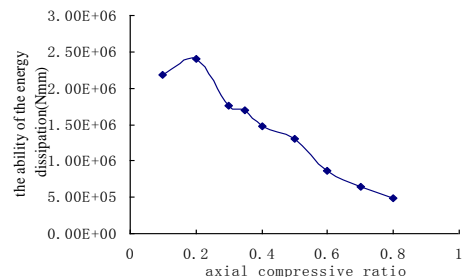

Fig. 11. The trend of the ability of the energy dissipation with the change of the axial compressive ratio

The accumulated area that is contained by hysteretic loop reflects the amount of energy dissipation in elastic-plasticity of the structure. Generally speaking, the fuller the hysteretic loop is, the stronger the ability of the energy dissipation becomes. Here the area contained by the skeleton curve in the first quadrant is adopted as the index to compare the ability of energy dissipation for each specimen. Obviously it's just a part of the total energy dissipation. Based on this comparison index, the condition of 9 specimens could be seen in Fig. 11. When axial compressive ratio is about 0.3 , the ability of energy consume is strongest. And the ability decrease obviously with the axial compressive ratio increases.

\section{Summary}

It could increase the load capacity of the specimen in some ranges by increasing the axial compressive ratio. With the increase of axial compressive ratio, the cracking load, the yield load and the failure load of the cross-section short-limb shear wall increases. When the axial compressive ratio increases more than 0.5 , the load capacity doesn't increase obviously. And the concrete at bottom would become cracking under compressive load if the axial compressive ratio is too high, which decrease the cracking load of the whole walling system. It could be concluded that it's most favorable when axial compressive ratio is about 0.3 .

From the change of the ductility factor and the ability of energy consuming, when axial compressive ratio is under low level, the ductility factor and the ability of energy consuming will increase with the increase of axial compressive ratio. But when the axial compressive ratio continue to increase, the axial compressive load become larger and larger, the ultimate displacement of wall become smaller and smaller and the ductility factor decreases sharply. When axial compressive ratio is about 0.3 , structure has the best ductility, which is beneficial to earthquake-resistance. As a result, in structure design it should be controlled around 0.3.

\section{References}

[1] Zhang Shoujun, Li Qingning, Li Rui, Fang Yunhong. Simulative analysis on the static elasto-plastic property of short-limb shear wall [J]. Sichuan Building Science, 2009,35(1),PP.16-18.

[2] Zhang Shoujun, Li Qingning, Xu Jienian. Simulative analysis on the static elasto-plastic property of short-limb shear wall [J]. J. Xi'an Univ. of Arch. \& Tech. (Natural Science Edition), 2006, 38 (2) PP.199-203, 226.

[3] Wang Jianxiang, Hu Jinglong1, Li Shuangxi, Su Fang. Finite Element Simulative Test of L-shaped Short-limb Shear Wall [J]. Journal of Shihezi University (Natural Science), 2009, 27(3)PP.345-349.

[4] Xiao Liangli, Gao Zhan, Zheng Yawen. The nonlinear analysis on short-limbed wall SLW with wing [J]. Sichuan Building Science, 2008， 34 (6) PP.61-62,73.

[5] Xiao Liangli, Chen Meng, Meng Huiying. ANSYS analysis of earthquake-resistant behavior of short-limbed walls [J]. World Earthquake Engineering, 2007,23 (2) PP.171-175.

[6] Zou Xuan. Nonlinear analysis of unconventionally shaped R/C frame structures [D].Shanghai Tongii University, 2004. 